\title{
ПЕРСУАЗИВНЫЙ ЭФФЕКТ ТРОПОВ В ПОЛИТИЧЕСКОМ ДИСКУРСЕ
}

\section{PERSUASIVE EFFECT OF FIGURES IN POLITICAL DISCOURSE}

A. Kotlova

Summary: The aim of the research within the framework of the stated topic is to analyze the features of reflection of the persuasive effect through the use of tropes in political discourse. The main issue of the study was to find out how tropes can influence the effect of persuasiveness in the texts of English political discourse. Accordingly, an analysis was conducted of a number of tropes appearing in British and American political discourse from the point of view of their impact on the persuasive effect. The main tropes studied were metaphors, epithets, irony, and hyperbole, since these are the most frequently encountered tropes in political discourse texts. Post-translation analysis, continuous sampling method, and generalization method were used as the main research methods. The research materials are texts of English and American political discourse: speeches by Donald Trump and Theresa May, as well as individual articles by English and American authors that deal with politics.

As a result of the conducted research, it was found that persuasiveness includes evaluative-emotive, advertising-agitation components, as well as elements of logical and statistical argumentation, which are used in political discourse in order to defend one's own point of view and incline both potential audience and opponents to it. In this case, numerous tropes, the main of which can be called metaphor, hyperbole, epithets and irony, act in political discourse as a kind of «enhancers» that ensure the persistence of political discourse.

The research materials, as well as the conclusions obtained by the author, can be used in the analysis of political discourse texts in terms of their impact on the audience. In addition, the research materials and the results obtained can be used to prepare courses of lectures and summaries of classes in such disciplines as «Political linguistics», "Linguistics», «Linguoculturology», «Theory and practice of translation», "Translation analysis», etc.

Keywords: persuasive effect of political discourse, tropes, arguments, politics, metaphor, potential audience, epithet, hyperbole.

\author{
Котлова Александра Сергеевна \\ Военный университет министерства обороны \\ Российской Федерации. \\ Al.kotlova@gmail.com
}

Аннотация: Целью исследования в рамках заявленной темы выступает анализ особенностей отражения персуазивного эффекта посредством использования тропов в политическом дискурсе. Основным вопросом исследования было выяснение, каким образом тропы могут оказывать влияние на эффект персуазивности в текстах англоязычного политического дискурса. Соответственно, был проведен анализ ряда тропов, встречающихся в английском и американском политическом дискурсе с точки зрения их влияния на персуазивный эффект. Основными исследованными тропами послужили метафоры, эпитеты, ирония и гипербола, поскольку именно эти тропы наиболее часто встречаются в текстах политического дискурса. В качестве основных методов исследования был использован постпереводческий анализ, метод сплошной выборки, а также метод обобщений. Материалами исследования послужили тексты английского и американского политического дискурса: выступления Дональда Трампа и Терезы Мэй, а также отдельные статьи английских и американских авторов, в которых речь идет о политике.

В результате проведенного исследования было установлено, что персуазивность включает в себя оценочно-эмотивные, рекламно-агитационные компоненты, а также элементы логической и статистической аргументации, которые используются в политическом дискурсе для того, чтобы отстоять собственную точку зрения и склонить к ней как потенциальную аудиторию, так и оппонентов. В данном случае многочисленные тропы, основными из которых можно назвать метафору, гиперболу, эпитеты и иронию, выступают в политическом дискурсе в качестве своего рода «усилителей», обеспечивающих персуазивность политического дискурса.

Материалы исследования, а также выводы, полученные автором, могут быть использованы в процессе анализа текстов политического дискурса с точки зрения особенностей их воздействия на аудиторию. Кроме того, материалы исследования и полученные результаты могут быть использованы для подготовки курсов лекций и конспектов занятий по таким дисциплинам, как «Политическая лингвистика», «Лингвистика», «Лингвокультурология», «Теория и практика перевода», «Переводческий анализ» и др.

Ключевые слова: персуазивный эффект, политический дискурс, тропы, аргументация, политика, метафора, потенциальная аудитория, эпитет, гипербола.
A ктуальность исследования заявленной темы обусловлена тем, что на современном этапе развития лингвистических исследований персуазивность не представляет собой устоявшегося термина, поскольку данное понятие трактуется разными исследователями весьма неоднозначно. Целью исследования является анализ персуазивного эффекта тропов в текстах англоязычного политического дискурса. Соответственно, представляется целесообразным проанализировать понятие персуазивного эффекта, а также особенности его функ- ционирования в политическом дискурсе на примере использования тропов в текстах англоязычных политических средств массовой информации. С этой целью был исследован ряд текстов политического дискурса, включающих такие тропы, как метафора, эпитет, гипербола и ирония.

В качестве теоретической базы исследования были использованы труды таких авторов в области языкознания, теории и практики перевода, как: Т.А. Ван Дейк, И.Ю. 
Логинова, М.Л. Гаспаров, Ц. Тодоров, Н.В. Степанова, Е.В. Жеребцова, Т.М. Голубева, Л.П. Крысин, С. Claridge, I. Pohl и др.

В результате проведенного исследования было выявлено, что персуазивность включает в себя оценочно-эмотивные, рекламно-агитационные компоненты, а также элементы логической и статистической аргументации, которые используются в политическом дискурсе для того, чтобы отстоять собственную точку зрения и склонить к ней как потенциальную аудиторию, так и оппонентов. В данном случае многочисленные тропы, основными из которых можно назвать метафору, гиперболу, эпитеты и иронию, выступают в политическом дискурсе в качестве своего рода «усилителей», обеспечивающих персуазивность политического дискурса.

Материалы исследования, а также выводы, полученные автором, могут быть использованы в процессе анализа текстов политического дискурса с точки зрения особенностей их воздействия на аудиторию.

Т.А. Ван Дейк под дискурсом понимал такое «комплексное коммуникативное явление, которое помимо текста также включает в себя еще и ряд экстралингвистических факторов (например, знаний о мире, мнений и точек зрения, установок, целей адресанта и т.д.), которые необходимы для того, чтобы понимать текст. ... Поток речи, то есть язык в его непрерывном движении, который вбирает в себя все многообразие исторического периода, индивидуальных и общественных характеристик как коммуниканта, так и ситуации общения, в рамках которой оно имеет место» [1, с. 8-9]. Соответственно, под политическим дискурсом целесообразно понимать весь объем текстов, в которых имеет место отображение политической и идеологической практик конкретных стран, отдельных политических партий и течений в рамках отдельного исторического периода, посредством которых идет актуализация общественного сознания.

Тексты политического дискурса в настоящий период времени анализируются, главным образом, с точки зрения практической перспективы в качестве действительности таких форм речевого поведения, которые выступают в качестве стратегических и ориентированных на успех адресанта в рамках коммуникативного процесса. Кроме того, целью таких текстов является оказание воздействия на адресата, причем намеренное и без какого-либо явного принуждения. Создавая тексты политического дискурса, адресант старается привлечь получателя на свою сторону посредством использования языковых или экстралингвистических средств. Таким образом, эти типы текстов могут рассматриваться в качестве носителей определенных функций коммуникации, которые представляют собой способ передачи персуазивных пропозиций $[11$, с. 256]. Наличие такого рода функций коммуникации предполагает, что имеет место осуществление определенного типа коммуникации, которая и рассматривается в качестве персуазивной.

Составляющими политической персуазивности являются оценочно-эмотивные и рекламно-агитационные компоненты, а кроме того, отдельные составляющие логической и статистической аргументации. Реализация персуазивного потенциала текстов политического дискурса имеет место посредством применения тактик позитивной самопрезентации, дискредитации оппонента, интимизации изложения, формирования очевидности и общеизвестности излагаемых явлений, а также обещаний и предложений готовых решений (выходов из ситуации). Эти тактики, в свою очередь, могут осуществляться посредством использования ряда языковых средств, основными из которых можно назвать метафоры, риторические вопросы, упоминание или, наоборот, опущение агента в страдательных конструкциях, модальные глаголы и др. [6, с. 244]. В качестве основных факторов влияния персуазивной коммуникации в рамках политического дискурса можно назвать следующие: пресуппозиции «популярность / непопулярность», результатом которых является доверие или же, наоборот, недоверие к адресанту; порядок аргументации в персуазивном речевом акте; отбор конкретных аргументов; применение аргументации типа «за и против», а также использование таких параметров, которые находятся в прямой зависимости от адресата (сюда можно отнести половозрастную принадлежность, социально-экономический статус, уровень образования, эмоциональное состояние, политические взгляды и т.д.).

Достижение эффекта персуазивности возможно посредством использования в текстах политического дискурса различных тропов. Под тропом принято понимать риторическую фигуру, слово или выражение, которое используется в переносном значении для усиления образности языка или художественной выразительности речи. Тропы активно используются в подавляющем большинстве текстов политического дискурса. Необходимо отметить, что отграничить тропы от фигур речи не всегда представляется возможным, так как классификация отдельных фигур речи (например, эпитетов, сравнений, перифраза, гипербол и литот), вызывает разногласия у исследователей данного явления. Так, например, М.Л. Гаспаров полагает, что тропы представляют собой «фигуры переосмысления», то есть, разновидность фигур [2, с. 191].

В настоящий период времени отсутствует какая-либо общепринятая классификация тропов. Однако, начиная со второй половины XX столетия активные исследован тропов предпринимались многими учеными в рамках структуралистской парадигмы и неориторики. Среди основных исследователей данного явления можно назвать 
Р. Якобсона, Р. Барта, Ц. Тодорова, представителей Льежской школы и др. В качестве основных тропов этими исследователями было выделено три их разновидности, а именно: метафора, метонимия и синекдоха. Однако, попытки выявления одного исходного тропа из этих трех, причем такого, к которому были бы сводимы остальные два, дали крайне разноречивые результаты. Так, например, представители Льежской школы и Ц. Тодоров в качестве такого первичного тропа называют синекдоху, в то время как У. Эко - метафору [9, с. 51].

В качестве основных разновидностей тропов принято выделять такие, как: метафора, метонимия, синекдоха, эпитет, гипербола, дисфемизм, каламбур, литота, перифраз, аллегория, пафос, олицетворение, сарказм, ирония, эвфемизм.

Далее представляется целесообразным проанализировать, каким образом тропы формируют персуазивный эффект в текстах политического дискурса.

В качестве первого тропа можно рассмотреть метафору. Реализация персуазивной стратегии зачастую имеет место посредством актуализации когнитивного механизма метафоры [7, с. 87], что можно продемонстрировать на примере фрагмента интервью, в котором Дональд Трамп открыто противопоставляет себя бывшему президенту США Бараку Обаме:

В нижеприведенном отрывке Д. Трамп использует метафору для того, чтобы сравнить экономику с игрой, в которой имеются свои собственные правила:

And I'm not doing - I'm not playing by the same rules as Obama. And just so you understand, I'm playing a normalization economy, whereas he's playing a free economy. It's easy to make money when you're paying no interest. It's easy to make money when you're not doing any pay-downs, so you can't - and despite that, the numbers we have are phenomenal numbers [12].

По мере того, как актуализируется метафора «Economy is a Game» имеет место разворачивание двух сценариев, а именно: экономики в качестве сложного многоуровневого явления, которое сопоставляется со значительно более простым и «осязаемым» явлением игры.

В процессе реализации сценариев когнитивной метафоры имеет место проецирование элементов исходных ментальных пространств друг на друга по мере того, как разворачивается операция композиции, что приводит к ассоциации экономики с игрой, а принципов и законов ее развития - с правилами игры [8, с. 84]. В силу того, что Б. Обама с точки зрения Д. Трампа «играет» в свободную экономику (he's playing a free economy), у аудитории формируется допущение, в соответствии с которым в бленде (смешанном пространстве) Обама играет, нарушая правила, а если выражаться точнее, то он не соблюдает их. По мере разворачивания речевой конструкции это допущение подкрепляется рядом реплик, например: «lt's easy to make money when you're paying no interest. It's easy to make money when you're not doing any pay-downs». Что же касается самого Д. Трампа, то он «играет» в строгом соответствии с правилами, что подтверждается следующей фразой: «l'm playing a normalization economy».

В рамках проанализированного примера имеет место попытка Д. Трампа прибегнуть к тактике этикетирования, то есть, открытого противопоставления себя бывшему президенту США, а также к позитивной репрезентации самого себя и своего экономического курса, что направлено на дискредитацию Б. Обамы.

Метафора для создания персуазивного эффекта также содержится в следующем примере:

[Russia] has become an ingredient in the toxic mix of xenophobia and chauvinism that the official Russian media... repeatedly serve up [16].

Данную фразу можно перевести следующим образом: «Россия стала ингредиентом в ядовитой смеси ксенофобии и шовинизма, постоянно производимой официальными русскими СМИ». В этом примере хорошо видно, что идеи шовинизма, которые активно распространяются рядом средств массовой информации, сравниваются с «ядовитым коктейлем», которым восприятие мира может быть отравлено точно так же, как ядовитая пища может отравить человека.

В следующем примере для создания эффекта персуазивности использован такой троп, как ирония:

"Much of the load will fall on the U.S.», - wrote Martin Wolf in The Financial Times, "largely because the Europeans, Japanese and even the Chinese are too inert, too complacent, or too weak». The European Union has 500 million people, compared with America's 300 million. Britain, France, Germany, Italy and Spain are advanced economies whose combined population adds up to that of the United States. Many EU members have enjoyed for decades the enlightened progressive policies that Americans won't be getting until Jan.

20. Why then are they so «inert» that their economic fortunes depend on the despised, moronic Yanks? [15].

В данном случае автор использует иронию, а также уничижительное определение «янки», что направлено на усиление иронического эффекта. Пользуясь такими определениями, как «despised» и «moronic», автор репрезентирует мнение стран Европы о США. В данном случае ирония используется для того, чтобы акцентировать внимание на презрительном отношении к американцам, что, в свою очередь, ведет к негативному отношению читателей по отношению к тем, кто позволяет 
себе такого рода презрительные оценки, так как они делят мир на «своих» и «чужих». Помимо этого, читатель делает вывод о том, что если экономика стран Европы находится в прямой зависимости от «несчастных идиотов янки», то сами эти страны в таком случае заслуживают еще более низкой оценки. Иронией пронизан весь текст данного отрывка, в котором явно и скрыто критикуются государства «остального» мира, что также формирует соответствующее отношение к ним читателя.

В качестве следующего примера тропов, применяемых для создания персуазивного эффекта, можно назвать эпитеты, что можно продемонстрировать на примере статьи Дж. Коркорана «Medvedev Makes His Mark»:

Another example last month was a decree by Medvedev dismissing Police Colonel General Vladimir Pronin, head of the Moscow directorate of the interior ministry. Pronin had described a police major guilty of a drunken killing spree in a supermarket as «a good professional» [13].

В этом примере можно видеть, как меняется контекст интерпретации. Словосочетание «a good professional», которое в первоначальном контексте понимается в прямом смысле после того, как ему было придано новое окружение, меняет прямой смысл на обратный: «а police major guilty of a drunken killing spree in a supermarket», что отрицательно характеризует автора этого высказывания. Однако, необходимо отметить, что у читателя в данном случае отсутствует возможность ознакомления с первоначальным текстов, в котором это выражение было употреблено в первый раз, соответственно, читатель не может сказать, что именно имелось здесь в виду $[4$, c. 100]. Тем не менее, этот факт остается незамеченным читателем, что дает возможность автору этой статьи сформировать у адресата такое мнение, в котором он заинтересован.

Далее можно рассмотреть такой троп, как гипербола, поскольку данный троп очень часто употребляется для создания персуазивного эффекта в текстах политического дискурса.

Так, например, Тереза Мэй, которая была премьерминистром Великобритании и выступала в Солсбери, активно использует гиперболу, которая актуализирует не только повышенную социальную, но и политическую значимость описываемых ею событий. В ее парламентской речи от 14 марта 2018 года, содержится характеристика события, которая содержит такие гиперболы, как: «использование боевого отравляющего вещества в Европе» и «незаконное применение силы российским государством против Соединенного Королевства» на фоне «сложившейся модели агрессии российского государства в Европе и за ее пределами»:

They have treated the use of a military grade nerve agent in Europe with sarcasm, contempt and defiance. So Mr. Speaker, there is no alternative conclusion other than that the Russian State was culpable for the attempted murder of Mr. Skripal and his daughter - and for threatening the lives of other British citizens in Salisbury, including Detective Sergeant Nick Bailey. This represents an unlawful use of force by the Russian State against the United Kingdom. And as I set out on Monday it has taken place against the backdrop of a well-established pattern of Russian State aggression across Europe and beyond [14].

В первом предложении данного отрывка Тереза Мэй вместо топонима «Salisbury» (Солсбери) употребляет название части света «Еurope» (Европа), которое обладает обобщающим значением и при этом выступает в качестве указателя на место происшествия. Такой прием ведет к расширению масштаба описываемого события с точки зрения географии, а использование таких синонимов, как «unlawful use of force» (незаконное применение силы) и «aggression» (агрессия), ведет к увеличению значимости данного события с точки зрения политики. Принимая во внимание тот факт, что инциденты, в рамках которых имело место применение боевых отравляющих веществ в Европе, случались только во время Первой и Второй мировых войн, а термин «агрессия» Устав $\mathrm{OOH}$ определяет в качестве «применения вооруженной силу государством против суверенитета, территориальной неприкосновенности или политической независимости другого государства», то можно сделать вывод о том, что подобные слова и словосочетания представляют собой гиперболы.

В этом же выступлении Тереза Мэй называет то, что произошло, «угрозой национальной безопасности»:

So this debate is taking place, Mr. Speaker, because there is no greater responsibility for this House - for this government and for me as Prime Minister - than recognizing threats to our national security and acting to meet them [14].

Оценка, даваемая Терезой Мэй инциденту в Солсбери, значительным образом преувеличена. В соответствии с информацией, которая имеется на официальном ресурсе правительства Великобритании, в качестве наиболее значимых угроз национальной безопасности относятся следующие: терроризм, шпионаж, кибернетические атаки, а также распространение оружия массового поражения, могущих оказать негативное воздействие на национальную структуру Великобритании, что, в свою очередь, не дает возможно расценивать покушение на жизнь двух человек (британского и российского подданных) в качестве угрозы настолько большого масштаба и значения [3, с. 199]. Относительно вышесказанного вполне справедливым представляется замечание К. Клэридж о том, что контексту отводится огромная роль в интерпретации высказываний, содержащих гиперболу, так как то, что представляет собой преувеличение в одном случае, может не быть таковым в другом [10, с. 12]. Примерами, которые были проанализированы выше, 
также подтверждается наблюдение Л.П. Крысина, в соответствии с которым «гипербола может быть создана в контексте высказывания - посредством сдвига смысла слов и выражений от значения единичности к значению регулярности (постоянности) какого-либо действия, от конкретности к обобщенности и др.» [5, с. 118].

Таким образом, можно прийти к общему выводу о том, что использование многочисленных тропов в рамках политического дискурса обладает ярко выраженным персуазивным эффектом. Посредством использования различных тропов в текстах политического дискурса имеет место реализация функции убеждения через обращения к логосу, пафосу и этосу. Применительно к логосу использование тропов в политическом дискурсе дает возможность актуализировать повышенную общественную и политическую значимость тех событий, которые они характеризуют. Что касается пафоса, то посредством тропов выражается отрицательное эмоциональное отношение (негодование, возмущение) говорящего к тому предмету, лицу или действию, которое он описывает, причем в данном случае целью использования тропов для достижения персуазивного эффекта можно назвать попытку формирования аналогичных отрицательных эмоций у целевой аудитории, что, в свою очередь, является причиной частого применения тропов в текстах политического дискурса для того, чтобы раскритиковать и дискредитировать оппонента и его действия. Также необходимо отметить, что эффективность тропов в качестве инструмента убеждения в политическом дискурсе находится в сильной зависимости от этоса, под которым необходимо понимать условия речевой ситуации, которые детерминируют уместность их применения в зависимости от личности говорящего. Применение в политическом дискурсе разнообразных тропов, которые семантически и ситуационно соотносятся с профессиональной компетенцией и сферой деятельности участников политического дискурса, дает возможность более успешного принятия тропов аудиторией, причем их содержание адресат воспринимает в качестве правильного (неправильного) и соответствующего (не соответствующего) действительности, в зависимости от намерений говорящего.

\section{ЛИТЕРАТУРА}

1. Ван Дейк Т.А. Язык. Познание, Коммуникация. - М.: Прогресс, 1989. - 310 с.

2. Гаспаров М.Л. Историческая поэтика и сравнительное стиховедение (проблема сравнительной метрики) // Историческая поэтика: итоги и перспективы изучения. - М., 1986. - С. 188-209.

3. Голубева Т.М. Персуазивность гиперболы в политическом дискурсе (на материале высказываний британских политиков) // Science Journal of VolSU. Linguistics. - 2019. - Vol. 18. - №3. - C. 195-205.

4. Жеребцова Е.В., Юткина С.В. Персуазивная функция иронии в политическом дискурсе (на материале английского языка) // Наука без границ. - 2017. №12 (17). - C. 95-106.

5. Крысин Л.П. Гипербола в художественном тексте и в обыденной речи // Язык художественной литературы. Литературный язык: сб. ст. к 80-летию М.Б. Борисовой. - Саратов: Научная книга, 2006. - С. 112-120.

6. Логинова И.Ю. Персуазивность как механизм воздействия в политическом дискурсе: программа политической партии и манифест // Интерпретация. Понимание. Перевод: Сборник научных статей. - СПб.: Изд-во СПбГУЭФ, 2005. - С. 240-248.

7. Степанова Н.В. Роль концептуальной интеграции в реализации персуазивной стратегии в политическом интервью // Материалы VII межвуз. науч.-практ. конф. с междунар. участием «Актуальные проблемы языкознания», г. Санкт- Петербург, 22-23 апр. 2018 г. - СПб., 2018. - С. 86-92.

8. Степанова Н.В. Персуазивность vs эвазивность: стратегии в современном политическом интервью // ДИСКУРС. - 2019. - Т. 5. - №3. - С. 79-89.

9. Тодоров Ц. Поэтика // Структурализм: «за» и «против» (Сб. статей). - М.: Прогресс, 1975. - С. 37-113.

10. Claridge C. Hyperbole in English. A CorpusBased Study of Exaggeration. - Cambridge: Cambridge University Press, 2011. - 325 p.

11. Pohl I. Zu persuasiven Potenzen pragmatischer Präsuppositionen in Werbetexten // Hoffmann, Michael / Kessler, Christine (Hrsg.). Beitrage zur Persua-sionsforschung: unter besonderer Berücksichtigung textlinguistischer und stilistischer Aspekte. (Sprache System und Tätigkeit; Bd. 26). - Frankfurt au Main, 1998. - S. 255 -269.

12. Excerpts From Trump's Interview With The New York Times // The New York Times. URL: https://www.nytimes.com/2019/02/01/us/politics/trump-interviewtranscripts.html (дата обращения: 03.03.2019).

13. Medvedev Makes His Mark. - [Электронный ресурс]. - Режим доступа: URL: http://www.guardian.co.uk/commentisfree/2009/may/12/medvedev-russiaglasnost (дата обращения: 25.09.2020).

14. PM Commons Statement on Salisbury incident response (14.03.2018) // Gov.uk. - [Электронный ресурс]. - Режим доступа: URL: https://www.gov.uk/ government/speeches/pmcommons-statement-on-salisbury-incidentresponse-14-march-2018 (дата обращения: 25.09.2020).

15. The Pedophile Santa of Global Capitalism. - ЭЭлектронный ресурс]. - Режим доступа: URL: http:www.ocregister.com/articles/christmas-apart-world-2267866lives-grown (дата обращения: 25.09.2020).

16. The Unhistory Man // The Economist (03.09.2009). - [Электронный ресурс]. - Режим доступа: URL: http://www.economist.com/node/14363315 (дата 0бращения: 25.09.2020). 